\title{
INNOVATIVE HYBRID METHOD TO PRODUCE ULTRA-FINE GRAINED METAL SHEETS FOR MICRO FORMING
}

\author{
1'Jacek GOLIŃSKI, ${ }^{1}$ Wojciech PRESZ, 'Mahmoud Shafayat HUSSAIN \\ ${ }^{1}$ Warsaw University of Technology, Institute of Manufacturing Processes, Narbutta, Warsaw, Poland, EU, \\ jacek.golinski@pw.edu.pl,wwojciech.presz@pw.edu.pl, shafayat.mahmoud.dokt@pw.edu.pl
}

https://doi.org/10.37904/metal.2021.4110

\begin{abstract}
For micro forming process, the initial material of sheet metal is desired, with the thickness below $1 \mathrm{~mm}$. Miniature parts have tight dimensional tolerances and require low surface roughness. These qualities are relatively easy to achieve if the material of the sheets used are ultra-fine grained. This paper introduces a I-ECAP-R method to produce the above mentioned sheet metal. The method consists of sequential use of two multistage processes. The first process includes incremental pressing of a $3 \mathrm{~mm}$ thick sheet metal. The second one is multi-stage rolling to flatten the sheets. Initial runs using 1050 Aluminium have shown promising results. These were obtained with a help of two invented technological tests: MB, micro-blanking with a blank holder and MTE, micro-extrusion with tension. In both tests. The maximum shaping force increased by $16.5 \%$ and $24.7 \%$, respectively, and the tendency to locate deformations decreased, as evidenced by the shift of the points of maximum force in the direction of the punch displacement by $26.4 \%$ and $4.7 \%$, respectively. SEM studies of the fracture surfaces did not show significant differences in the nature of deformation processes ended with loss of cohesion. Both the UFG and CG material show similar bundle fracture.
\end{abstract}

Keywords: I-ECAP-R, UFG materials, technological tests, microforming

\section{INTRODUCTION}

The stormy development of various types of microdevices [1], which has been observed for several decades, causes a gradual increase in the demand for metal micro-parts [2] They must be characterized by high dimensional accuracy and surface smoothness [3,4]. These requirements are met by metal forming processes, during which, by eliminating the cracking phenomenon, it is possible to obtain surfaces with theoretically atomic smoothness. Reducing the dimensions of objects produced by this method causes the so-called scale/size effects $[5,6]$ Their influence on the course of processes and product properties increases with the reduction of the dimensions of the shaped object [7] and it cannot be ignored when the dimensions of the products are close to $1 \mathrm{~mm}$ [8]. This results in the definition of microforming, distinguished as a new technology. Microforming is the plastic shaping of objects with at least two overall dimensions of approx. $1 \mathrm{~mm}$ [9]. The most frequently considered scale effects are: the volume effect - usually combined with the size of the material grain $[10,11,12]$ and the surface effect [5] - associated with the surface layer. The first has an impact on the quality and performance of the micro-parts, and the second on contact phenomena such as friction [13] and the tendency to adhesive bonding [14]. The effect of scale may also occur in the construction of microtools [15,16] and process design [17]. Very low energy expenditure needed to produce micro-parts causes frequent use of unconventional methods of supporting processes, such as the use of lasers $[18,19,20]$ and vibrations of various frequencies $[21,22,23]$ An effective method of microforming is the use of progressive dies, i.e. shaping products from the strip through successive operations, until the final separation of the product [24, 25]. This method replaces the inter-operational transport, which is troublesome in the case of micro-objects. The volume effect of scale occurs when the dimensions of the product are comparable with the grain size of the material used [7]. A natural method of avoiding this unfavorable effect is to use UFG (ultrafine grained) 
materials with a reduced grain size as opposed to CG (coarse grained). Often, such materials have unique mechanical properties as substantially greater strength, hardness and fatigue life [26]. On another hand the formability and ductility of the UFG materials are comparable or sometimes even better to CG material $[4,27]$. For the above reasons, there is a need for UFG tapes that can be used in microforming processes. The article proposes a I-ECAP-R method of obtaining such tapes.

\section{MATERIAL}

UFG materials with dimensions that can be used as a starting material for the construction of machine parts can be obtained in three main ways:

1) application to metals and metal alloys of unconventionally large deformation SPD (Severe Plastic Deformation) [28],

2) application of powder metallurgy,

3) crystallization of amorphous materials (metallic glasses).

The first of these methods resulted in the separation of a group of volumetric processes from metal forming, which are aimed at causing changes in the internal structure of the metal while minimizing changes in the overall dimensions of the processed material. A special position in the group of these processes is occupied by the ECAP (Equal Channel Angular Pressing) method, which consists in pressing the material through the angular channel. This method has limitations related to the shape of the processed material - slender and thin materials cannot be processed. It is also prone to friction problems - the surfaces of the processed materials must be very well lubricated. The development and modification of the ECAP method is the method of incremental squeezing through the angle channel I-ECAP (Incremental ECAP), which, supplemented by the rolling process, creates the I-ECAP-R method (see Figure 1).
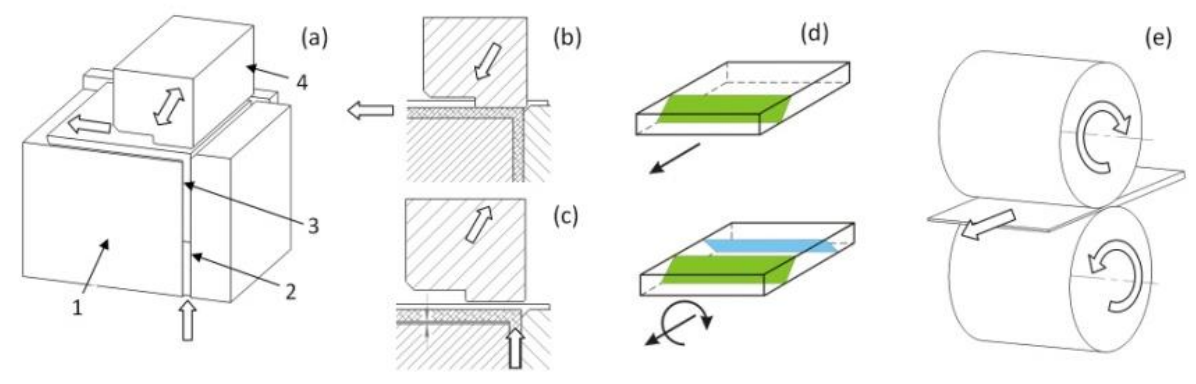

Figure 1 I-ECAP-R process

In the I-ECAP-R process (Figure 1a) the input material - 3 is moved through the die input channel - 1, through the pusher - 2. The pusher introduces the material into the shear zone, which is under the punch - 4 . Placing the material under the punch it does not take place continuously, but is cyclical. First, the pusher moves the material into the shear zone (Figure 1c). After the material is moved, the pusher supports the material and the punch moves down, cutting the given portion of material (Figure 1b). The efficiency and quality of the process depend on the stroke length of the follower. The magnitude of the pusher stroke must therefore be small enough for the plastic deformation regions to overlap. Such an overlay will allow to obtain a homogeneous structure of the processed material with a grain size below $1 \mu \mathrm{m}$ [29]. The material used in the process, 1050 aluminium in a semi-hard condition with a thickness of $3 \mathrm{~mm}$, requires the use of a pusher stroke of $0.6 \mathrm{~mm}$. This value should be considered as limiting with regard to the device used. This implies a minimum thickness of the obtained plate preform, which is $3 \mathrm{~mm}$. The production of the UFG structure requires 8 material passes through the angular channel. The material on subsequent passes must be introduced into the die entry channel so that the shear planes intersect during the process, rather than being parallel. In order 
to achieve such a system of shear planes, the load is rotated around its axis by 180 in successive passes (Figure 1d). The processes of microforming with the use of progressive methods and the production of preforms by the micro-blanking method require the use of sheets with a thickness not exceeding $1 \mathrm{~mm}$. This is why the I-ECAP-R process was created. After the eighth pass, the material was cut into $8 \mathrm{~mm}$ wide strips and rolled successively. In the next passages (40x), the thickness was reduced by $0.05 \mathrm{~mm}$. Ultimately, during the rolling process, the material thickness was reduced to $1 \mathrm{~mm}$, which made it possible to obtain a strip with a length of approx. $300 \mathrm{~mm}$. For comparison, $8 \mathrm{~mm}$ wide strips (along the direction of the rolling mill) were cut from the same $10503 \mathrm{~mm}$ thick aluminium sheet in a semi-hard state from which the $100 \times 100 \mathrm{~mm}$ samples were cut for the I-ECAP-R process. They were then rolled using the same procedure as in the I-ECAP-R process. The tapes were $8 \mathrm{~mm}$ wide, $1 \mathrm{~mm}$ thick and approx. $300 \mathrm{~mm}$ long.

\section{TECHNOLOGICAL TESTS}

Two tests based on literture research [30] were designed for the analysis of the obtained tapes:

1) Micro-Blanking with a blank holder - MB (see Figure 2a and Figure 2c)

2) Micro-Tension-Extrusion - MTE with parameters enabling the occurrence of biaxial stretching of the free surface and tearing of the collar in conditions similar to the tensile test (see Figure $\mathbf{2 b}$ and Figure $\mathbf{2 d}$ ).
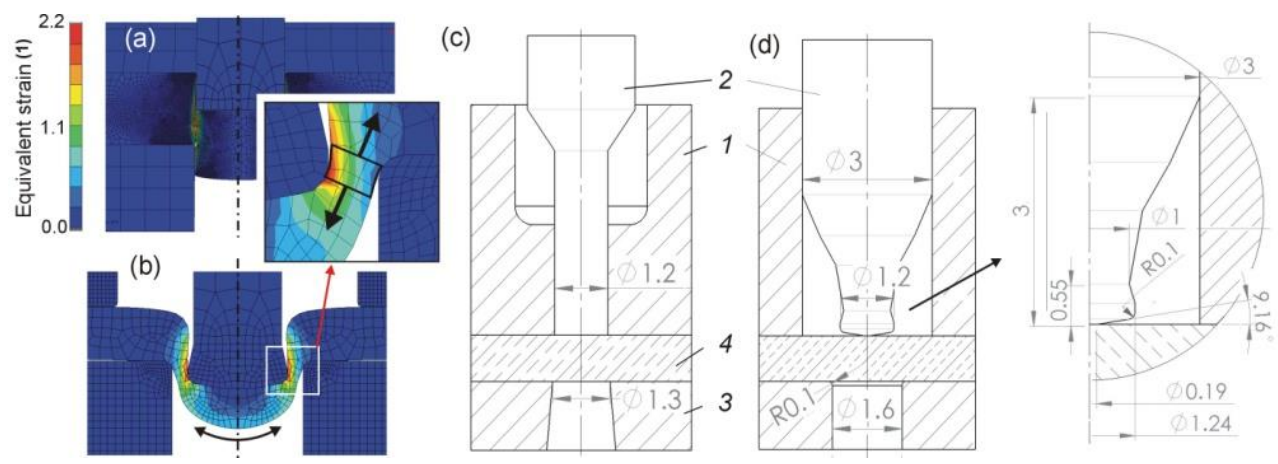

Figure 2 Technological tests; FEM - Equivalent strain distribution (a) MB, (b) MET; Tool design of: (c) MB, (d) MET, where 1 - blank holder, 2 - punch, 3 - die, 4 - strip

\subsection{Test Systems}

The experimental stand consists of 3 key parts. Namely the Hounswield 10NS testing machine, micro die set and computer. The diagrams of the die-sets used are shown in Figure $\mathbf{2 c}$ and Figure $\mathbf{2 d}$. The force of the blank holder is exerted by the screws. Detailed descriptions of the devices can be found in previous works. The testing machine is equipped with force transducer (load cell) that needs to be connected to the computer to record readings. The press machine is capable of generating and recording a force in the range of 0 to $10 \mathrm{kN}$ with an accuracy of $0.01 \mathrm{~N}$. The stroke length of the press machine is $400 \mathrm{~mm}$ and can be controlled to an accuracy of $1 \mu \mathrm{m}$.

\subsection{The Test procedure}

The samples for both tests have the same dimensions $7 \times 1 \times$ approx. $12 \mathrm{~mm}$ and are cut from the prepared tapes. In view of the planned SEM tests, the surfaces of the samples were carefully smoothed with a metallographic grinder. The process of thorough surface preparation resulted in a significant reduction in the thickness of the samples. Ultimately, the thickness of the specimens for MB and MET process is $0.8 \mathrm{~mm}$ and $0.76 \mathrm{~mm}$, respectively. The blank holder pressure was exerted by screws. Both tests are performed under the same kinematic conditions as allowed by the numerically controlled testing machine. Machine oil is used for 
lubrication. During the test, the punch head moves down at $1 \mathrm{~mm} / \mathrm{min}$ velocity. In case of MB the punch head stops right at the surface of the die, in case of MET it stops $0.2 \mathrm{~mm}$ below the die surface. During the whole process the force measurements are recorded using the computer and the software. Each trial was repeated at least three times. Shown in the Figure $\mathbf{3 a}$ and Figure $\mathbf{3 f}$. The runs of forces are the runs determined as the average of 3 trials.

\section{RESEARCH RESULTS AND THEIR ANALYSIS}

As a result of the technological tests, records of the course of process forces and test micro-components were obtained, which were: in the case of MB, blanks, and in the case of MET, deformed samples. The obtained materials were analysed, as a result of which representative results were selected, the discussion of which is presented below.
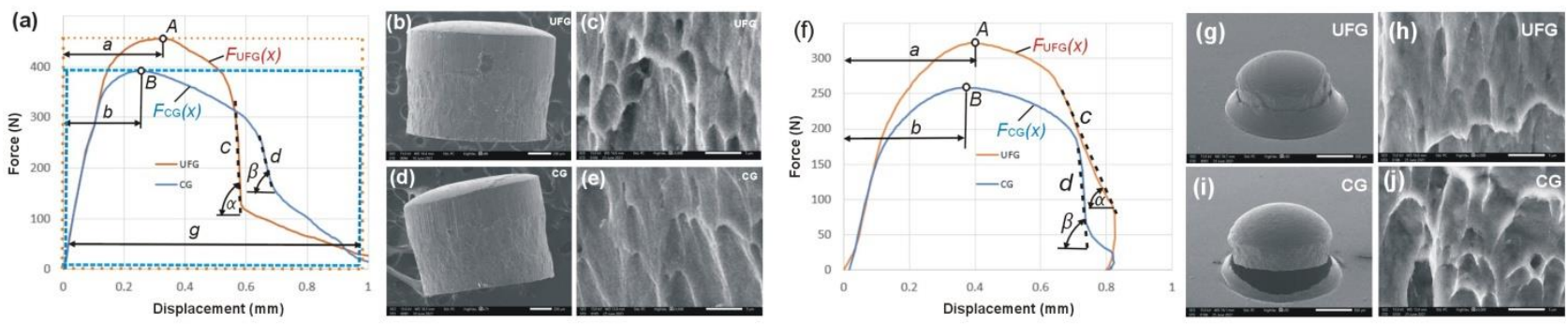

Figure 3 Tests results; Force flow: (a) MB, (f) MET; SEM MB: blanks overview: (b) UFG, (d) CG, fracture zone: (c) UFG, (e) CG; SEM MET samples overview: (g) UFG, (i) CG, fracture zone: (h) UFG, (j) CG

In the MB process shown in the Figure 1a, maximum process force $F_{\mathrm{UFG}}$ in point $A$ is $16.5 \%$ higher for UFG material than for CG material. It should also be noted that the point of maximum process force $A$ in the case of UFG is shifted in the direction of punch movement by $26.7 \%$ in relation to point $B$. This proves the later concentration of strains. On the other hand, the decrease in force in the final stage of the process is faster for UFG than for CG, the angle $\alpha$ of the segment $c$ (in relation to the horizontal axis) is greater than the angle $\beta$ of the segment $d$. This suggests faster development cracking phenomena in UFG material. In the blanking processes, a parameter that helps in the assessment of the material's tendency to fracture is the graph fill factor (1).

$\lambda=\frac{\int_{0}^{g} F_{\text {proc }}(x) d x}{F_{\text {max }} \cdot g}$

where: $F_{\text {proc }}$ - process force $(\mathrm{N}), F_{\max }$ maximum process force $(\mathrm{N}), g$ - sheet metal thickness $(\mathrm{mm})$.

The higher it is, the lower the material's tendency to crack. Under MB conditions for UFG material $\lambda U F G=0.78$, and for $C G$ material, $\lambda_{C G}=0.65$, and therefore $\lambda_{U F G}>\lambda_{C G}$, which suggests a greater tendency to cracking of UFG material than CG material. SEM analysis showed in both cases the presence of a fracture surface typical of bundle-type cracking. It is worth emphasizing that the material subjected to enormous plastic deformation by repeated shearing and rolling retained internal cohesion and remained a relatively ductile material - capable of further plastic deformation.

In the MTE process shown in the Figure 3f, the maximum process force - point $A$ for UFG material, is $24.7 \%$ higher than the maximum process force for CG material - point $B$. Point $A$ is shifted in the direction of punch movement by $4.7 \%$ in relation to point $B$. This difference proves a slight increase in the stable plastic deformation capacity. Pay attention to this, see the Figure $\mathbf{2 b}$ - close out of FEM result, that in the final stage of the process, the flange that forms the material in the area between the die and the punch is uniaxially stretched. UFG material undergoes less severe constriction leading to loss of cohesion than CG material. This is evidenced by a slower decrease in force in the final phase of the process, $\alpha<\beta$, and a longer segment 
of this decrease $c>d$. It should be assumed that in the case of UFG material, the collar narrows relatively uniformly over the entire area, and the fracture occurs along the entire circumference. The CG material rapidly breaks only in part of the circumference, and then the canopy formed is folded back, which remains coherent in a small part of the circumference, as shown in Figure $\mathbf{3 i}$.

\section{CONCLUSIONS}

The conducted exploratory studies on the adaptation of UFG materials produced by the I-ECAP-R method for use in microforming allow for the formulation of the following conclusions.

The innovative I-ECAP-R hybrid process was implemented, enabling the production of ultra-fine-grained tapes intended for microforming.

Two micro-processes were designed as technological tests of new UFG materials in the form of tapes:

- Micro-blanking process with a blank holder - MB,

- $\quad$ Micro-extrusion process with stretching - MTE.

The usefulness of the designed tests for the evaluation of the deformability of UFG materials produced by the I-ECAP-R method was demonstrated. Based on the conducted research, it was found that the modification of the structure of 1050 aluminium in the semi-hard state by means of the I-ECAP-R increased the maximum forming force in the MB test and MTE test by $16.5 \%$ and $24.7 \%$, respectively. It also reduced the tendency to locate deformations, as evidenced by the shift of the maximum forming force points in the direction of the punch displacement in the MB and MTE processes by $26.4 \%$ and $4.7 \%$, respectively.

SEM studies of the fracture surfaces did not show any significant differences in the nature of deformation processes ending with loss of cohesion. Both the UFG and CG material had similar structures corresponding to the bundle-type crack.

\section{ACKNOWLEDGEMENTS}

Studies were funded by project granted by Warsaw University of Technology under the program Excellence Initiative: Research University (ID-UB, 504/04496/1104/45.010501 and 504/04496/1104/45.010502).

\section{REFERENCES}

[1] KHANNA, R. MEMS fabrication perspectives from the MIT Microengine Project. Surface and Coatings Technology. 2003, vol. 163-164, pp. 273-280.

[2] ALTING, L., KIMURA, F., HANSEN, H.N., BISSACCO, G. Micro Engineering. CIRP Annals. 2003, vol. 52, no. 2, pp. 635-657.

[3] JOO, B.Y., RHIM ,S.H., OH, S.I. Micro-hole fabrication by mechanical punching process. Journal of Materials Processing Technology. 2005, vol. 170, no. 3, pp. 593-601.

[4] XU, J., WANG, X., WANG, C., YUAN, L., CHEN, W., BAO, J., SU, Q., XU, Z., WANG, CH., WANG, Z., SHAN, D., GUO, B. A Review on Micro/Nanoforming to Fabricate 3D Metallic Structures. Advanced Materials. 2021, vol. 33, no. 6, article no. 2000893.

[5] XU, Z., PENG, L., BAO, E. Size effect affected springback in micro/meso scale bending process: Experiments and numerical modeling. Journal of Materials Processing Technology. 2018, vol. 252, pp. 407-420.

[6] RAULEA, L.V., GOIJAERTS, A.M., GOVAERT, L.E., BAAIJENS, F.P.T. Size effects in the processing of thin metal sheets. Journal of Materials Processing Technology. 2001, vol. 115, no. 1, pp. 44-48.

[7] KONG, D., SUN, S., XIN, T., XIAO, L., SHA, X., LU, Y., MAO, S., ZOU, J., WANG, L., HAN, X. Reveal the size effect on the plasticity of ultra-small sized $\mathrm{Ag}$ nanowires with in situ atomic-scale microscopy. Journal of Alloys and Compounds. 2016, vol. 676, pp. 377-382. 
[8] ENGEL, U., ROSOCHOWSKI, A., GEIßDÖRFER, S., OLEJNIK, L., CHINESTA, F., CUETO, E. Microforming and nanomaterials. Advances in Material Forming. 2007, pp. 99-124.

[9] GEIGER, M., KLEINER, M., ECKSTEIN, R., TIESLER, N., ENGEL, U. Microforming. CIRP Annals Manufacturing Technology. 2001, vol. 50, no. 2, pp. 445-462.

[10] ZHENG, Q., SHIMIZU, T., YANG, M. Grain size effect on mechanical behavior of thin pure titanium foils at elevated temperatures. International Journal of Mechanical Sciences. 2017, vol. 133, pp. 416-425.

[11] YEH, F.H., LI, C.L., LU, Y.H. Study of thickness and grain size effects on material behavior in micro-forming. Journal of Materials Processing Technology. 2008, vol. 201, no. 1-3, pp. 237-241.

[12] RAJENTHIRAKUMAR, D., SRIDHAR, R., ABENETHIRI, R., KARTIK, R., BAGRI, D. Experimental investigations of grain size effects in forward microextrusion. International Journal of Advanced Manufacturing Technology. 2016, vol. 85, no. 9-12, pp. 2257-2264.

[13] ENGEL, U. Tribology in microforming. Wear. 2006, vol. 260, no. 3, pp. 265-273.

[14] SKOWROŃSKA, B., CHMIELEWSKI, T., PACHLA, W., KULCZYK, M., SKIBA, J., PRESZ, W. Friction weldability of UFG 316L stainless steel. Archives of Metallurgy and Materials. 2019, vol. 64, no. 3, pp. 1051-1058.

[15] SCHUBERT, A., JAHN, S.F., MÜLLER, B. Modular tool concept and process design for micro impact extrusion. Precision Engineering. 2014, vol. 38, no. 1, pp. 57-63.

[16] PRESZ, W., CAKCO, R. Application of complex micro-die for extrusion of micro-rivets for micro-joining. In: Metal 2017, 26th International Conference on Metallurgy and Materials. Ostrava: TANGER, 2017, pp. 514-520.

[17] PRESZ, W., CACKO, R. Influence of micro-rivet manufacturing process on quality of micro-joint. AIP Conference Proceedings. 2011, vol. 1353, pp. 541-546.

[18] GAO, H., CHENG, G.J. Laser-induced high-strain-rate superplastic 3-D microforming of metallic thin films. Journal of Microelectromechanical Systems. 2010, vol. 19, no. 2, pp. 273-281.

[19] OCAÑA, J.L., MORALES, M., GARCÍA-BALlESTEROS, J.J., PORRO, J.A., GARCíA, O., MOLPECERES, C. Laser shock microforming of thin metal sheets. Applied Surface Science. 2009, vol. 255, no. 10, pp. 5633-5636.

[20] LIU, F., LIU, H., JIANG, C., MA, Y., WANG, X. Experimental and numerical investigations of a novel laser impact liquid flexible microforming process. Metals. 2018, vol. 8, no. 8, no. 599.

[21] HUNG, J.C., TSAI, Y.C. Investigation of the effects of ultrasonic vibration-assisted micro-upsetting on brass. Materials Science and Engineering A. 2013, vol. 580, pp. 125-132.

[22] PRESZ, W. Dynamic effect in ultrasonic assisted micro-upsetting. AIP Conference Proceedings. 2018, vol. 1960, no. 100012.

[23] PRESZ, W., CACKO, R. Ultrasonic assisted microforming. In: Metal 2017, 26th International Conference on Metallurgy and Materials. Ostrava: TANGER, 2017, pp. 521-526.

[24] FU, M.W., CHAN, W.L. Micro-scaled progressive forming of bulk micropart via directly using sheet metals. Materials and Design. 2013, vol. 49, pp. 774-783.

[25] FU, M.W., ZHENG, J.Y., MENG, B. A Review of Progressive and Compound Forming of Bulk Microparts by Using Sheet Metals. MATEC Web of Conferences. 2018, vol. 190, no. 1001.

[26] DIEHL, A., ENGEL, U., GEIGER, M. Influence of microstructure on the mechanical properties and the forming behaviour of very thin metal foils. International Journal of Advanced Manufacturing Technology. 2010, vol. 47, pp. 53-61.

[27] KAWASAKI, M., AHN, B., KUMAR, P., JANG, J., LANGDON, T.G. Nano- and Micro-Mechanical Properties of Ultrafine-Grained Materials Processed by Severe Plastic Deformation Techniques. Advanced Engineering Material. 2017, vol. 19, no. 1, pp. 1-17.

[28] EDALATI, K. Review on Recent Advancements in Severe Plastic Deformation of Oxides by High-Pressure Torsion (HPT). Advanced Engineering Materials. 2019, vol. 21, no. 1, pp. 1-10.

[29] ORŁOWSKA, M., BRYNK, T., HÜTTER, A., GOLIŃSKI, J., ENZINGER, N., OLEJNIK, L., LEWANDOWSKA, M. Similar and dissimilar welds of ultrafine grained aluminium obtained by friction stir welding. Materials Science and Engineering A. 2020, vol. 777, no. 139076.

[30] JI, K., LIU, Y., LIU, S., ZHANG, Y. A review on the microblanking technology of metallic foils. International Journal of Advanced Manufacturing Technology. 2021, vol. 114, no. 11-12, pp. 3185-3200. 